\title{
Experimental investigation of two-phase pressure drop in rough minichannels
}

\author{
Wacławczyk Paweł, Ulbrich Roman \\ Opole University of Technology, Opole 45-271, Mikołajczyka 5, Poland \\ E-mail: pawelwaclawczyk@onet.pl,r.ulbirch@po.opole.pl
}

\begin{abstract}
Following the general tendency of miniaturization of devices in many branches of industry, smaller and smaller components are used. Mini channels are used to construct mini heat exchangers and mini reactors. Because of this fact, predicting two-phase pressure drops along the mini tube plays an important role already at the design stage. It defines the proper and safe operating conditions of such devices. It was decided to research this phenomena in five single mini channels and undertake a comparison of various correlations models reported in literature and check how the process of changing critical Reynolds value affects the conformity of the experimental data and results reported in literature. It was found that the Mishima-Hibiki model derived from literature offers the possibility of most accurate mathematical modelling. It was also found that changing critical Reynolds value because of mini channel roughness can significantly improve the accuracy of the existing correlations models e.g. for Lee-Lee model the improvement is equal to almost $9 \%$.
\end{abstract}

\section{Introduction}

Two-phase flow is used in production processes in a variety of systems in such branches as petrochemical, medical, automotive, space and integrated electronic industries. One of the most important parameters in the two-phase flow is undoubtedly associated with pressure drops along the line. The mathematical description of this phenomenon for two-phase mixture flow is much more difficult than in the case where only one phase flows in the channel.

Nowadays, the tendency of miniaturization of devices can be observed in nearly all branches of industry. Consequently, there is a need to use smaller and smaller tubes in the devices. Because of this fact, there is a need to research two-phase flow pressure drops in minichannels. This pressure drop phenomenon has an influence on the correct exploitation of devices such as mini heat exchangers or mini reactors. Such a phenomenon also brings about the fact that mechanical engineers need to predict pressure drops occur during exploitation of the machines already at the design stage. This determines safe and proper operation of such appliances.

Throughout the years of the twentieth century, a number of publications describing the pressure drop correlations undertook the topic of two-phase mixture flow. In most cases the studies in these papers reported the phenomena in channels with a hydraulic diameter ranging from $\mathrm{d}_{\mathrm{h}}=20 \mathrm{~mm}$; therefore, relatively accurate calculation methods for such conditions can be found in the literature. An important aspect of two-phase pressure drop research is concerned with determination of the boundaries between the conventional and mini and also micro channel.

However it is hard to find an agreement between the authors of literature in this area. This leads to the difficulties in the comparison of their results. Some researchers believe that the distinction of channels should not only depend on the diameter but also on the properties of the mixture flow. Following consideration of various classifications of channels in the literature, a decision was made to apply the upper boundary of the hydraulic diameter of the mini channel to be $6 \mathrm{~mm}$.

It was also decided that the major objectives of this research should include:

(1) development of a new database for two-phase flow pressure drops along mini channel,

(2) assessment of the accuracy of previous correlations designed for predicting pressure drop characteristics,

(3) consideration of the roughness of mini channel, therefore proper selection of critical Reynolds number and finding the relations between the results reported in the literature and ones gained from the experiment,

\footnotetext{
a Corresponding author: pawelwaclawczyk@onet.pl, r.ulbrich@po.opole.pl
} 
(4) comparison of the results for the classical critical Reynolds number and the ones gained for another critical Reynolds number.

\section{Methodology}

Research into energy losses of the flowing two-phase mixture was conducted for flow through vertical minichannels. Due to the fact that instantaneous fluctuations occur during two-phase flow, the measurements of differential pressure applied an electrical manometer and data acquisition system in the place of the common U-tube. It was concluded that particularly for the case of intermediate patterns it is necessary to refer to the mean pressure drop value in the considerations.

\subsection{Test module}

In order to analyze and assess the correlation models of pressure drop, a test module was designed and built (Fig. 1 and Fig.2), which was applied for the determination of the values of pressure drop along the length of the minichannel, consisting of [Wacławczyk, Hapanowicz, Ulbrich 2013]:

$\checkmark$ five separate mini-channels (1) with a length of $\mathrm{L}=$ $600 \mathrm{~mm}$, made of plexiglas by means of joint routing method. Each of the channels has a square crosssection and their hydraulic diameter was equal to $\mathrm{dh}=2,3,4,5$ and $6 \mathrm{~mm}$, respectively,

$\checkmark$ air compressor (2) and liquid pump (3),

$\checkmark$ liquid tank (4),

$\checkmark$ gas (5) and liquid rotameters (6), serving for the purpose of determination of the specific volume fractions of the phases,

$\checkmark$ electrical manometer manufactured by PELTRON (7),

$\checkmark$ A PC (8) with MatLAB software for the purposes of instantaneous mean values of pressure drops,

$\checkmark$ a disk for data acquisition and storage (9).

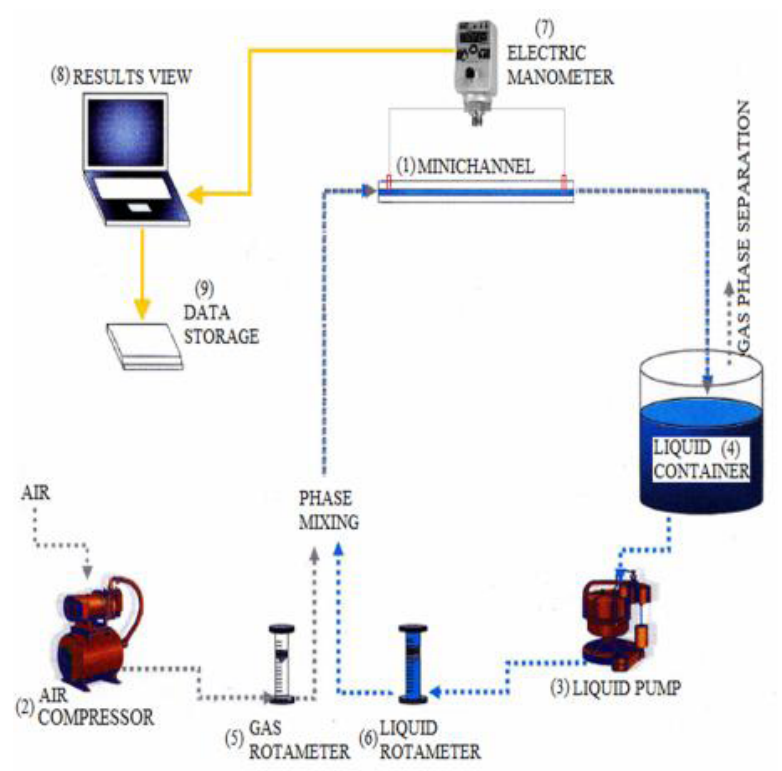

An important aspect of the conducted research was associated with the measurement of roughness of the minichannel walls using a thickness gauge. It was concluded that the channels used in the research had the roughness parameter since the derived mean roughness depth of $\mathrm{k}=5 \mu \mathrm{m}$.

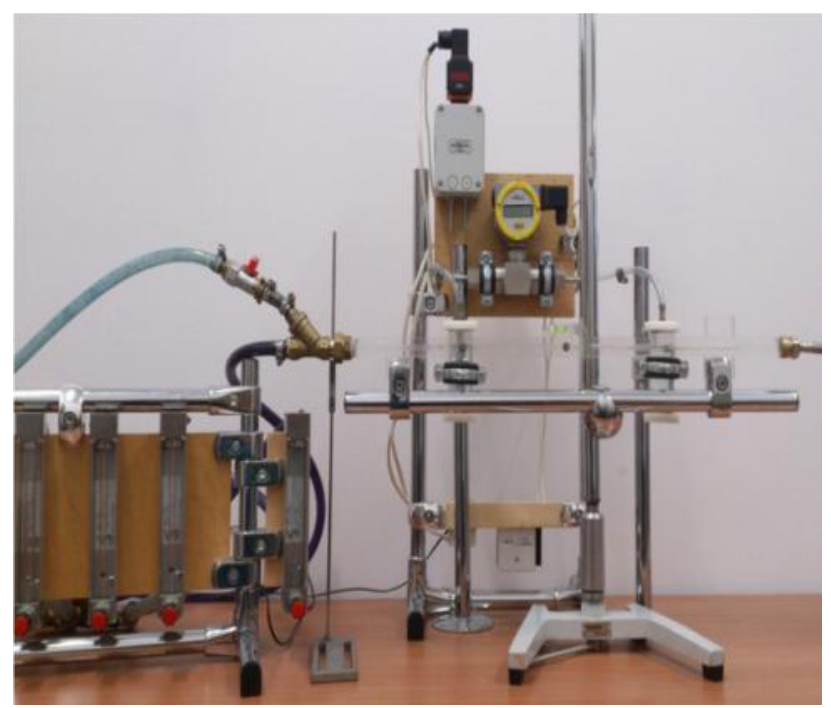

Fig.2. Photo of the test module.

\section{Calculations}

It was decided to analyze two-phase flow correlation models, prepared for conventional and mini channel covered in the literature to check how the changing process of the critical Reynolds number affects the conformity of the data. Mean absolute error was used to assess the accuracy of previous correlation models:

$$
\mathrm{MAE}=\frac{1}{\mathrm{n}} \sum \frac{\left|\Delta \mathrm{P}_{\text {pred }}-\Delta \mathrm{P}_{\text {exp }}\right|}{\Delta \mathrm{P}_{\exp }} 100 \% .
$$

Lockhart-Martinelli correlation model is one of the most popular tools for predicting pressure drop characteristics in the two-phase flow mixture. Therefore, the initial analysis was based from this classical model. Lockhart and Martinelli in a paper from 1949 [Lockhart, Martinelli 1949] determined the upper border of laminar flow to be $\mathrm{Re}_{\mathrm{cr}}=1000$, while lower limit of turbulent flow to be $\mathrm{Re}_{\mathrm{cr}}=2100$. Authors did not define what character the flow has when the value of Reynolds number is in the ambiguous area from $1000-2100$. In the range of laminar flow the following equation was used to determine the pressure drop ratio $\lambda$ :

$$
\lambda=\frac{a}{\operatorname{Re}}
$$

where $\mathrm{a}=57$ because of mini channels square-cross section.

Because of fact that the surface roughness of the mini channels walls had already been identified, it was decided to use the Haalands equation (3) instead of the Blasius one (4) (according to [Drobniak 2008]):

Fig. 1. Test module design. 


$$
\begin{gathered}
\frac{1}{\sqrt{\lambda}}=-1,8 \log \left[\frac{6,9}{\operatorname{Re}}+\left(\frac{k / d}{3,7}\right)^{1,11}\right], \\
\lambda=\frac{0,3164}{R e^{0,25}} .
\end{gathered}
$$

Fig. 3 shows the curves of the function according to different equations which describe pressure drop ratio $\lambda$. As it can be seen on the graph, the stepwise change of value $\lambda$ occurs for critical Reynolds number $\mathrm{Re}_{\mathrm{cr}}=2100$ (point $\mathrm{A}$ and $\mathrm{A}^{\prime}$ ). Therefore, it was decided to indicate point $\mathrm{B}$ at the border of laminar flow disappearance. Its location occurs atthe intersection of the line which expresses the value of $\lambda$ for laminar fluid flow in a square-cross section channel (line (2)) with function (2) (line (4)). Finally, for the purpose of this research, $\mathrm{Re}_{\mathrm{cr}}=$ 770 as the final value of critical Reynolds number was established [Wacławczyk, Hapanowicz, Ulbrich 2013].

Chisholms equation (5) were used to calculate the Lockhart-Martinelli parameter, where the C constant depends on liquid and gas flow characters (table 1) [Chisholm 1967].

$$
\Phi_{L}^{2}=1+\frac{C}{X_{L M}}+\frac{1}{x_{L M}^{2}}
$$

Next,Friedelmodel analysis could be applied for predicting pressure drops in two-phase flow along conventional channels [Friedel 1979]. In his research, author developed a model based on 25,000 data points which could be used to identify channels which have hydraulic diameter larger than $4 \mathrm{~mm}$.

The main equation of this model is [Friedel 1979]:

$$
\phi_{L}^{2}=A_{1}+\frac{3,34 A_{2} A_{3}}{F r^{0,045} W e^{0,035}},
$$

where:

$$
A_{1}=(1-x)^{2}+x^{2} \frac{\rho_{L} \lambda_{G}}{\rho_{G} \lambda_{L}}
$$

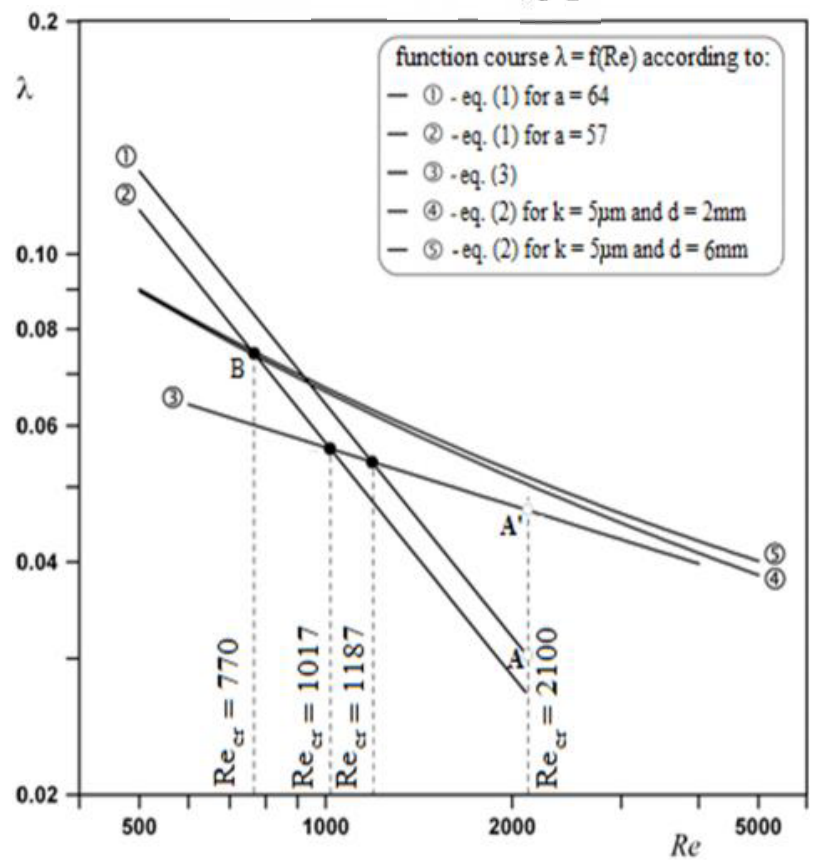

Fig.3. Function curve according to different equations [Wacławczyk, Hapanowicz, Ulbrich 2013].

$$
\begin{gathered}
A_{2}=x^{0,78} *(1-x)^{0,24}, \\
A_{3}=\left(\frac{\rho_{L}}{\rho_{G}}\right)^{0,91}\left(\frac{\eta_{G}}{\eta_{L}}\right)^{0,19}\left(1-\frac{\eta_{G}}{\eta_{L}}\right)^{0,7} \\
F r=\frac{m_{T P}^{2}}{g d_{h} \rho_{T P}^{2}} \\
W e=\frac{m_{T P}^{2} d_{h}}{\rho_{T P} \sigma_{L}}
\end{gathered}
$$

Table 1. C value for the equation (5).

\begin{tabular}{|c|c|c|}
\hline $\mathrm{C}$ & liquid flow & gas flow \\
\hline 5 & laminar & laminar \\
\hline 10 & laminar & turbulent \\
\hline 12 & turbulent & laminar \\
\hline 20 & turbulent & turbulent \\
\hline
\end{tabular}

For the case of homogeneous model, Mc Adams equations were used to determine density and viscosity of the two-phase flow mixture [Mc Adams 1954]:

$$
\begin{aligned}
& \frac{1}{\rho_{T P}}=\frac{x}{\rho_{G}}+\frac{1-x}{\rho_{L}} . \\
& \frac{1}{\eta_{T P}}=\frac{x}{\eta_{G}}+\frac{1-x}{\eta_{L}} .
\end{aligned}
$$

The first paper where the authors determined border between laminar and turbulent flow as in other than classical manner $\mathrm{Re}_{\mathrm{cr}}=2100$ was appear by MullerSteinhagen and Heck [Muller-Steinhagen, Heck 1986]. In their model, the authors assumed the value of critical Reynolds number to be 1187 , and used an equation to calculate this value in the form:

$$
R e_{L, G}=\frac{m_{T P} d_{h}}{\eta_{L, G}}
$$

where $m_{T P}$ is two-phase flow mass velocity $\left[\mathrm{kg} / \mathrm{m}^{2} \mathrm{~s}\right]$. This model is based on the function of three parameters:

$$
\left(\frac{\Delta P}{L}\right)_{T P}=H(1-x)^{1 / 3}+B x^{3},
$$

where:

$$
\begin{gathered}
H=A+2(B-A) x, \\
A=\left(\frac{\Delta P}{L}\right)_{L}=\lambda_{L} \frac{m_{T P}^{2}}{2 \rho_{L} d_{h}}, \\
\mathrm{~B}=\left(\frac{\Delta \mathrm{P}}{\mathrm{L}}\right)_{\mathrm{G}}=\lambda_{G} \frac{m_{T P}^{2}}{2 \rho_{G} d_{h}} .
\end{gathered}
$$

The models based on mini channels was reported in research by Mishima-Hibiki [Mishima-Hibiki 1996] and Lee-Lee [Lee-Lee 2001] and their correlations. Both are a derivative of the classical Lockhart-Martinelli model and propose a different way of determining constant $\mathrm{C}$ from the Chisholm equation.Mishima and Hibiki, in their paper, found $\mathrm{C}$ to be equal to:

$$
C=21\left(1-e^{-0,319 d_{h}}\right),
$$

and Lee-Lee correlations determines constant $C$ by using the equation:

$$
\mathrm{C}=\mathrm{c}_{1} \varphi^{\mathrm{c}_{2}} \psi^{\mathrm{c}_{3}} \mathrm{Re}_{\mathrm{Lo}}^{\mathrm{c}_{4}},
$$

where:

$$
\varphi=\frac{\eta_{\mathrm{L}}^{2}}{\rho_{\mathrm{L}} \sigma \mathrm{r}_{\mathrm{h}}}
$$




$$
\psi=\frac{\eta_{\mathrm{L}}\left(\mathrm{u}_{\mathrm{L}}+\mathrm{w}_{\mathrm{G}}\right)}{\sigma} .
$$

The values of constants $c_{1}, c_{2}, c_{3}, c_{4}$ depend on the parameters of two phase mixture flow.

Table 2. Values of constants $\mathrm{c}_{1}, \mathrm{c}_{2}, \mathrm{c}_{3}, \mathrm{c}_{4}$ for equation (21).

\begin{tabular}{|c|c|c|c|c|}
\hline $\begin{array}{c}\text { Flow } \\
\text { character } \\
\text { istics of } \\
\text { liquid/gas } \\
\text { phase }\end{array}$ & $\mathrm{c}_{1}$ & $\mathbf{c}_{\mathbf{2}}$ & $\mathbf{c}_{\mathbf{3}}$ & $\mathbf{c}_{\mathbf{4}}$ \\
\hline $\begin{array}{c}\text { laminar / } \\
\text { laminar }\end{array}$ & $6,833^{*} 10^{-8}$ & $-1,317$ & 0,719 & 0,557 \\
\hline $\begin{array}{c}\text { laminar / } \\
\text { turbulent }\end{array}$ & $6,185^{*} 10^{-2}$ & 0 & 0 & 0,726 \\
\hline $\begin{array}{c}\text { turbulent / } \\
\text { laminar }\end{array}$ & 3,627 & 0 & 0 & 0,174 \\
\hline $\begin{array}{c}\text { turbulent / } \\
\text { turbulent }\end{array}$ & 0,408 & 0 & 0 & 0,451 \\
\hline
\end{tabular}

Two more correlation models were analysed and compared to the remaining ones. Those models applied mathematical prediction of two-phase pressure drops along the flow in micro channels. Authors of these methods conducted measurements in channels with a hydraulic diameter smaller than $1 \mathrm{~mm}$.

In a paper from 2003,Qu and Mudawar reported results from the research of twenty one parallel micro channels with the size of a single one of $0.2 \times 0.7 \mathrm{~mm}$. Based on this measurement, authors decided to define constant $\mathrm{C}$ based on the equation:

$$
\mathrm{C}=21\left(1-\mathrm{e}^{-0,319 \mathrm{~d}_{\mathrm{h}}}\right)\left(0,00418 \mathrm{~m}_{\mathrm{TP}}+0,0613\right) \cdot(22)
$$

Next model developed on the basis of micro channel research was the one by Kawahara et. al. Authors decided to measure the phenomena of two-phase flow in micro channel whose size was $0,1 \times 0,1 \mathrm{~mm}$. During the tests, authors found that the best conformity with the literature data was achieved when $\mathrm{C}$ constant is just 0.24 [Kawahara et.al 2002].

\section{Results}

The charts (Figure 4 and 5) and table 3 contain the results of two-phase flow pressure drop prediction for different correlation models from literature together with their comparison and details of conformity gained for another critical Reynolds number.

The first of the analyzed calculation models of pressure drop during two-phase mixture flow was the LockhartMartinelli correlation model. It was established that in connection with the occurrence of the roughness of minichannel wall, laminar flow can change into turbulent for a smaller Reynolds number than the classically accepted value of 2,100. An improvement in the precision of the results was obtained at the level of $8 \%$ as a result of application of the critical Reynolds number of 770 .
Due to this fact, a decision was made to analyze a subsequent method used to calculate pressure drop, developed for the flow of two-phase mixture through conventional channels, mini and micro channels.

For the majority of the analyzed methods, the process of adopting other critical Reynolds number led to the improvement of the results.

Particularly good results in this respect were gained for the models developed for mini channels, in which case satisfactory precision was gained already for the value of $\operatorname{Re}=2100$.

For the Mishima-Hibiki model, the best conformity was gained with the experimental data from among the analyzed calculation models. It is undoubtedly connected with the fact that the size of the channel for which the calculations were made are similar to the sizes of the channels used in the authors' original research. The application of the critical Reynolds number at 770 made it possible to improve the precision of the calculations of both models (for the case of the Lee-Lee method by nearly 9\%)

Table 3. Statistical parameters for analyzed correlations.

\begin{tabular}{|c|c|c|}
\hline \multirow{2}{*}{ Correlation model } & \multicolumn{2}{|c|}{ MAE [\%] } \\
\cline { 2 - 3 } & $\mathrm{Re}_{\mathrm{cr}}=2100$ & $\mathrm{Re}_{\mathrm{cr}}=770$ \\
\hline Lockhart-Martinelli & 40,7 & 32,4 \\
\hline Friedel & 64,0 & 53,2 \\
\hline Homogeneous & 30,5 & 28,4 \\
\hline Muller-Steinhagen, Heck & 39,0 & 39,0 \\
\hline Mishima-Hibiki & 28,6 & 25,9 \\
\hline Lee-Lee & 37,6 & 29,0 \\
\hline Qu-Mudawar & 90,6 & 98,9 \\
\hline Kawahara et al.. & 64,7 & 62,8 \\
\hline
\end{tabular}

For the case of the models developed for the two-phase flow through conventional channels, the process of varying Reynolds number has also brought positive effects. A surprise is connected with the registered conformity with the experimental data for the case of the homogenous model, as it is considered to be very imprecise by many authors. For the case of the Friedel model, $11 \%$ improvement was gained as a result of applying $\mathrm{Re}_{\mathrm{Cr}}=770$. However, the value of the absolute error at the level of $53.2 \%$ is still unsatisfactory. This is due to the fact that the author of this method developed it on the basis of channels with the hydraulic diameters below $4 \mathrm{~mm}$. For channels this size, the results of the reported research also offers satisfactory results. On the contrary, for the channel size $d_{h}=2$ and $3 \mathrm{~mm}$, 
a)

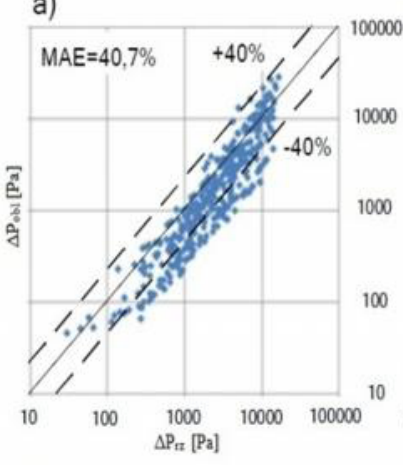

b)

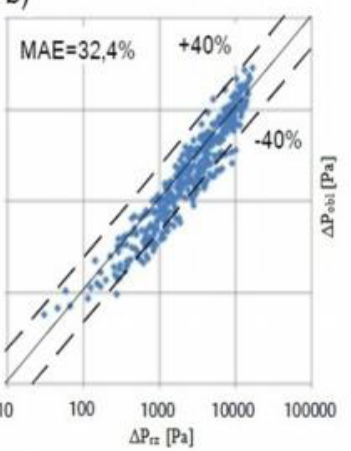

c)

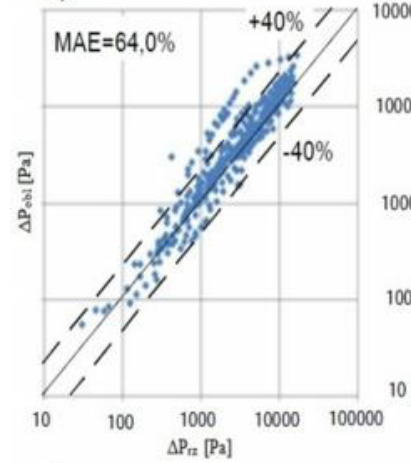

d)

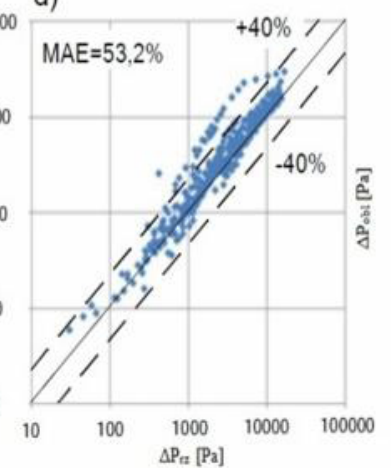

e)
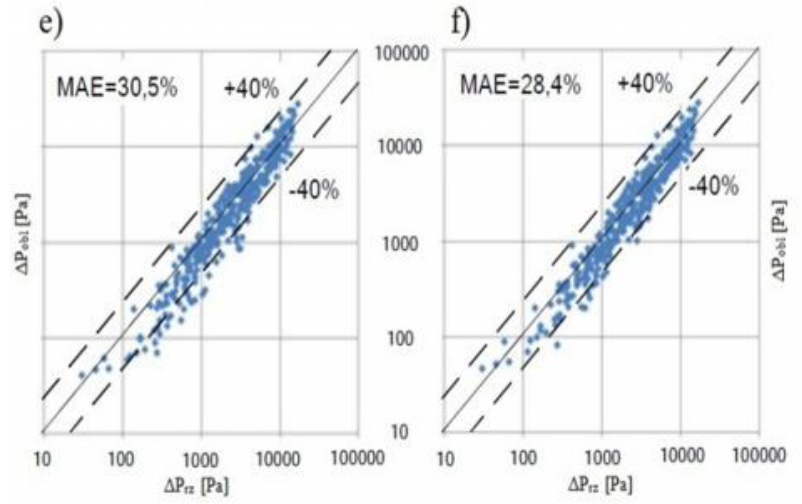

g)

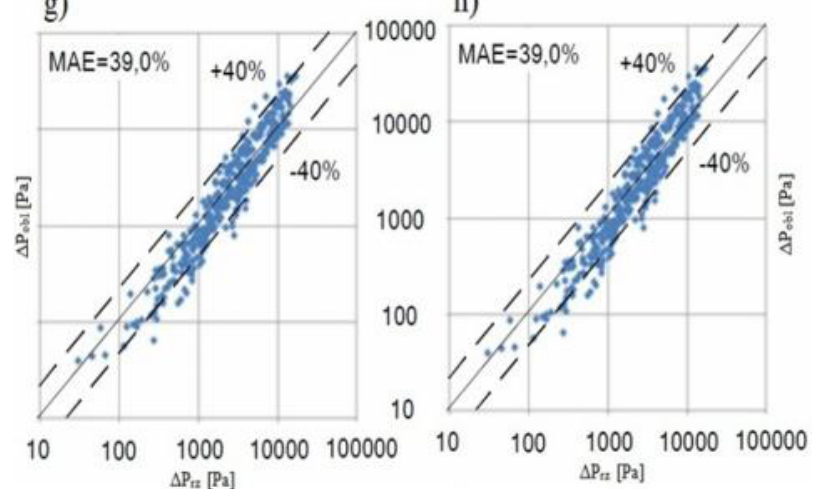

Fig. 4. Comparison of the values of calculated pressure drops and experimental ones for following correlations: a) LockhartMartinelliRe $_{\mathrm{cr}}=2100$, b) Lockhart-MartinelliRe $\left.\mathrm{crr}=770, \mathrm{c}\right)$ FriedelRe $\mathrm{e}_{\mathrm{cr}}=2100$, d) FriedelRe $\mathrm{e}_{\mathrm{cr}}=770$, e) homogeneous $\mathrm{Re}_{\mathrm{cr}}$ $=2100$, f) homogeneous $\operatorname{Re}_{\mathrm{cr}}=770$, g) Muller-Steinhagen, Heck $\left.\operatorname{Re}_{\mathrm{cr}}=2100, \mathrm{~h}\right)$ Muller-Steinhagen, Heck $\operatorname{Re}_{\mathrm{cr}}=770$.

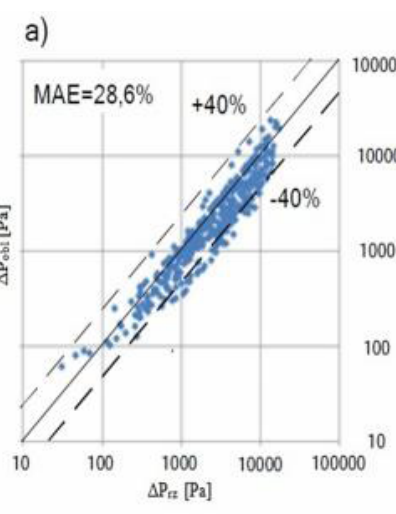

b)
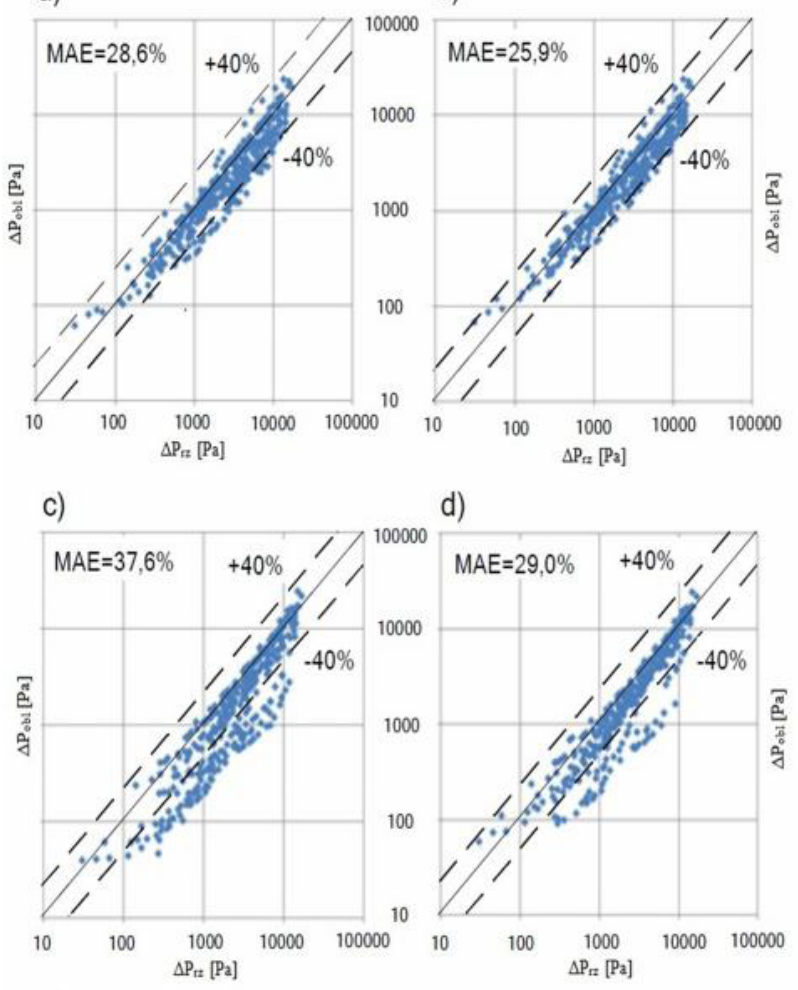

d)
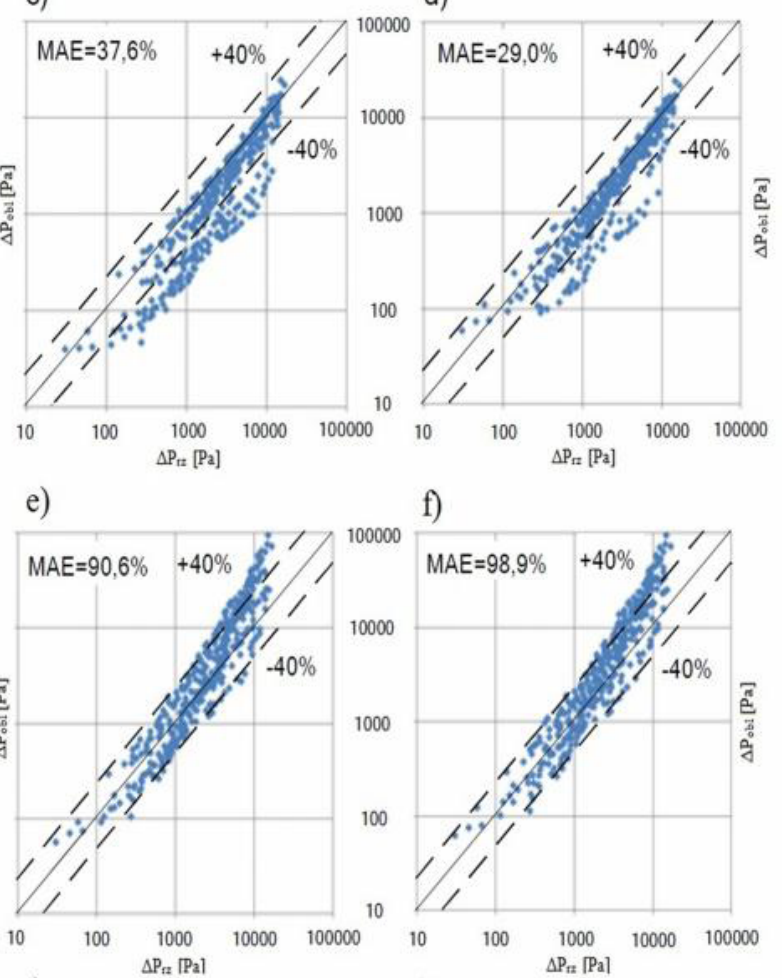

g)

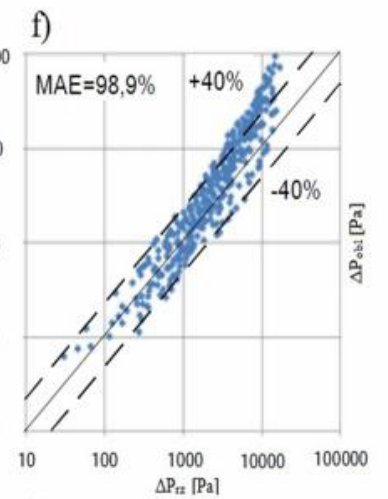

h)

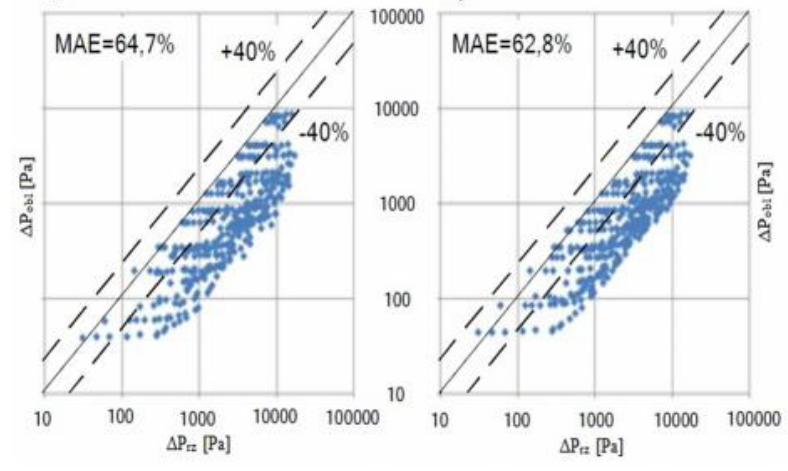

Fig.5. Comparison of the values of calculated pressure drops and experimental ones for following correlations: a) MishimaHibikiRe $_{\text {cr }}=2100$, b) Mishima-HibikiRe $e_{\text {cr }}=770$, c) Lee-Lee $\mathrm{Re}_{\mathrm{cr}}=2100$, d) Lee-Lee $\mathrm{Re}_{\mathrm{cr}}=770$, e) Qu-MudawarRe $\mathrm{e}_{\mathrm{cr}}=$ 2100, f) Qu-MudawarRe $\mathrm{e}_{\mathrm{cr}}=770$, g) Kawahara et al. $\mathrm{Re}_{\mathrm{cr}}=$ 2100, h) Kawahara et al. $\operatorname{Re}_{\mathrm{cr}}=770$. 
the absolute error had a high value, which had a considerable effect on the mean value in the total population of data.

For the case of the Muller-Steinhagen and Heck model it was possible to conclude that the process of varying the critical Reynolds number did not have any effect on the precision of the results. This is due to the fact that the value of the Reynolds number calculated by means of equation (14) assumes the results considerably above 2,100 .

Due to the considerably smaller size of the micro channels, on the basis of which the models by QuMudawar and Kawaharaet al. were developed, the precision of the calculated pressure drops during twophase flow are unsatisfactory and the process of applying the critical Reynolds number at 770 led to deterioration in the precision of these models.

\section{Conclusions}

The study allowed to formulate the following conclusions:

$\checkmark$ An important consideration in the research of twophase mixture flow is associated with accounting for the roughness of its walls.

$\checkmark$ For the case of the conventional correlation models, the process of the correction of the critical Reynolds number from $\mathrm{Re}_{\mathrm{cr}}=2100$ to $\mathrm{Re}_{\mathrm{gr}}=770$ in a majority of cases led to the increase of the precision due to the consideration of these models to be rough. This in turn resulted in the value of the absolute error of these models in the range $\mathrm{MAE}= \pm 30 \%$. In the literature of the subject, as a result of considering the complexity of the process of two-phase flow, such a range is considered to be sufficiently precise. Consequently, this enables the use of such models for the calculations of the pressure drop of the two-phase mixture in minichannels.

$\checkmark$ It was indicated that for the case of the computation methods developed for mini channels, the process of variation of the critical Reynolds number results in a considerable improvement of the precision of calculations (by $8 \%$ for the Lee-Lee model).

$\checkmark$ For the case of correlation models developed for microchannels, the manner in which $\mathrm{Re}_{\mathrm{cr}}$ was corrected did not bring forecasted results. This is due to the considerably smaller dimensions of the walls of the mini channels used in the research in comparison to the ones used in the authors' own study.

$\checkmark$ It was indicated that the process of varying the critical Reynolds number from the non-homogeneity range 500-2,100 (Fig. 2) considerably affects the improvement of precision of in hydraulically rough mini channels.

$\checkmark$ The analysis of the effect of the patterns in two-phase flow on pressure drops in gas-liquid mixture passing through mini channels was adopted to better purpose of the further testing, and in particular in the consideration of the intermediate patterns.

\section{References}

1. Chisholm D., A theoretical basis for the LockhartMartinelli correlation for two-phase flow, Int. J. Heat Mass Transfer, t.10, s.1761, 1967

2. Friedel F., European Two-Phase Flow Group Meeting, Ispra, Italy, Paper E2, 1979

3. Lee H., Lee S.Y, Pressure drop correlations for two-phase flow with horizontal channels with low aspect ratios, Int. Journal of Multiphase Flow, 27, 2001, 2043-2062

4. Lockhart R.W., Martinelli R.C., Proposed correlation of data for isothermal two-phase twocomponent flow in pipes, Chem. Eng. Progr., , t.45, no. 1, s.39,1949

5. Kawahara A., Chung P.M.-Y., Kawaji M.,Investigation of two-phase flow pattern, void fraction and pressure drop in microchannel, International Journal of Multiphase Flow 28, 14111435,2002

6. Mc Adams W.H.,Heat Transmission, Mc Graw-Hill, New York 1954

7. Mishima K., Hibiki T.,Some characteristics of airwater two-phase flow in small diameter vertical tubes, Int. Journal of Multiphase Flow, 22, 1996, 703-712

8. Muller-Steinhagen H., Heck K., A simple pressure drop correlation for two-phase flow in pipes, Chem. Eng. Process, t.20, s.297,1986

9. Qu W., Mudawar I., Measurement and prediction of pressure drop in two-phase micro-channel heat sinks, International Journal of Heat and Mass Transfer 46, 2737-2753, 2003

10. Wacławczyk P., Hapanowicz J., Ulbrich R., Badania oporów przepływu jedno- $i$ dwufazowego w minikanałach, Inżynieria i Aparatura Chemiczna nr 5, s. 494-495, 2013

11. Drobniak S., Mechanika płynów, Politechnika Częstochowska, 2008 